\title{
ESCRITAS DA PRÓPRIA VIDA / COM VIDA PRÓPRIA: AUTOBIOGRAFIA EM A FAVOR DO VENTO
}

\author{
JIAN MARCEL ZIMMERMANN (IFSUL) ${ }^{1}$
}

\begin{abstract}
RESUMO: Este trabalho tem como intuito refletir sobre uma modalidade narrativa amplamente difundida na contemporaneidade, a autobiografia. Contudo, nem todos os tipos de textos desta categoria são relevantes para nosso estudo, interessa-nos sua vertente literária, as autobiografias que galgam o status de arte. Claro está que não se trata de um gênero estanque ou limitado às formas convencionais, sendo um de nossos propósitos verificar as soluções estéticas de renovação deste objeto. Como corpus de análise, elegemos o romance $A$ favor do vento (2014), de Duca Leindecker, músico com larga e bem-sucedida carreira, principalmente como líder da banda Cidadão Quem, e escritor de três livros, com boa aceitação do público leitor, sendo seu primeiro livro, A casa da esquina, um bestseller, com mais de doze edições. Julgamos que A favor do vento configura-se como uma autobiografia não convencional, pelo uso de artifícios que manejam constantemente a ação de cifrar e decifrar, dando ao leitor relevante tarefa na efetivação do texto literário. Ademais, independentemente do gênero que se atribui a tal romance, ele se sustenta esteticamente em função de sua estrutura, que explora de forma criativa diversos elementos da narrativa. A avaliação das possibilidades estéticas utilizadas nas narrativas em que autor e personagem compartilham o mesmo contexto axiológico é, sem dúvida, uma reflexão pungente na contemporaneidade, e nosso propósito aqui é modestamente contribuir na construção deste panorama tão variado.
\end{abstract}

PALAVRAS-CHAVE: Literatura Contemporânea. Autobiografia. Duca Leindecker.

ABSTRACT: This paper has the purpose of arguing about a very popular kind of novel in the actuality, the autobiography. However, it's not all kinds of these texts that matters to us, we are interested in its literary mode, the autobiographies that wish to be considered like art. Obviously this is not a genre restricted to the conventional forms, and one of our objectives is to check out the aesthetic solution to renew this object. We chose to analyze the novel A Favor do Vento, by Duca Leindecker, a musician with a large and well succeeded career, mainly as a leader of the band Cidadão Quem, and writer of three books, with success between the readers. His first book, for example, A Casa da Esquina, is a best seller, with more than twelve editions. We consider that A Favor do Vento is as an unusual autobiography, because it works all the time on hiding and showing, giving to the reader a very important job on the effectiveness of the literary text. In addition, we think that, no matter what kind of genre we include this novel on, it maintains itself, based on its structure that works, in a creative way, many aspects of the narrative. The evaluation of the aesthetics possibilities used on the autobiographies is, no doubt, a relevant discussion on the actuality, and with this paper we desire to modesty contribute to build a so wide field.

KEYWORDS: Contemporary Literature. Autobiography. Duca Leindecker.

\section{INTRODUÇÃO}

O presente estudo problematiza certos aspectos da relação entre a biografia do escritor com o mundo ficcional vivido por seus personagens. Trata-se, em primeira instância, do entrecruzamento de duas categorias distintas da narrativa (autor e personagem), mas que implica em inúmeras outras, dependendo da estratégia construtiva adotada. Tal problematização decorre de uma grande quantidade de produções contemporâneas com esta

\footnotetext{
${ }^{1}$ Doutor em Letras pela Universidade Federal do Rio Grande do Sul. Pós-Doutor em Literatura pela Universidade Federal de Santa Catarina. Professor do Programa de Pós-Graduação em Linguagens do Instituto Federal SulRio-Grandense (IFSUL), campus Pelotas.
} 


\section{$=$ TRAMA $=$}

configuração, a maioria delas muito lidas, mas ainda pouco estudadas. É a busca de compreensão dos meandros da arquitetura de tais textos que objetivamos aqui, dos componentes e estratagemas estéticos que efetivam na teoria uma relação que na prática é bem-sucedida.

O corpus de análise escolhido para este fim é o romance $A$ favor do vento (2014), de Duca Leindecker, músico nacionalmente conhecido, principalmente por liderar a banda de Rock Cidadão Quem, e escritor com público leitor significativo. Nestas circunstâncias, abundam em nosso meio as autobiografias e biografias de artistas; Duca, entretanto, recorre a outro expediente, utiliza-se da mescla entre eventos fatuais e ficcionais, com exploração criativa dos elementos da narrativa. Sem almejar a associação de seus textos à rotulação teórica, seus romances não são autobiografias tradicionais, tampouco pretendem velar as relações entre autor e personagens, criando uma produtiva mescla.

O texto, a partir da configuração supracitada, passa a ter vivência própria, com a possibilidade de associação com o portador da forma (o autor), mas com autonomia suficiente para proporcionar fruição estética sem que se estabeleça uma analogia autobiográfica. Deste modo, o texto flui, de escrita sobre a própria vida, passa a ser escrita com vida própria.

\section{ESCRITA DA PRÓPRIA VIDA}

Boa parte das narrativas literárias produzidas hoje em dia apresenta o foco narrativo centrado na primeira pessoa. Certamente há explicações sociológicas ou psicossociais para tal ocorrência (individualismo do mundo contemporâneo; carência de contato entre as pessoas; etc.), entretanto, o que chama a atenção, ademais, é o fato de muitas destas narrativas tratarem do enredo da vida (ou de parte dela) do sujeito que escreve, seja em forma de diários, autobiografias, biografias, depoimentos, etc.

Georg Lukács já afirmava, em Teoria do romance (2000), que a essência deste gênero é biográfica, tendo em vista que, em última instância, sempre se está a contar sobre eventos da vida de alguém. Na contemporaneidade, todavia, essa premissa deixa a estrutura profunda do romance para evidenciar-se na superfície narrativa, tornando-se uma das variantes mais difundidas e consumidas.

Podemos definir a autobiografia (ou a biografia), minimamente, como um texto no qual se percebe vínculos entre os eventos constantes no enredo ficcional com os efetivamente vividos pelo autor da obra, seja através de um enredo completo ou de forma episódica. A definição etimológica é deveras esclarecedora neste sentido: "A palavra é um composto de três elementos gregos: autós ("próprio", "de si mesmo"); bios ("vida"); e gráphein ("escrever"): é o autor que descreve a história de sua própria vida."(D’ONOFRIO, 2002, p. 124)

Tal escrita de si, ou outras similares, entretanto, nem sempre é designada como obra artística (literária), e, por vezes, nem almeja tal condição. Para enquadrar-se nesta categoria, D’Onófrio (2002, p. 124) elenca algumas características necessárias:

\footnotetext{
Uma autobiografia, portanto, só pertence à literatura, num sentido estrito, quando o autor consegue o extravasamento do seu eu, fazendo uso da linguagem poética, revestindo os fatos de sua vida com ideias, sentimentos, emoções. Lembramos mais uma vez: arte é ficção, não realidade, muito embora seja difícil ou até impossivel estabelecer limites entre os dois mundos.
}

Durante muito tempo, a biografia e a autobiografia foram consideradas gêneros menores, em um tempo em que, de maneira geral, acreditava-se no "gênio criativo" como algo sobrenatural, em detrimento do árduo trabalho que desempenhavam os escritores. A partir do 
momento em que tais crenças perderam relevância, leitores passaram a ver com menos ressalvas textos literários que fossem elaborados a partir de eventos do mundo factual.

Propomo-nos, nesta análise, a evitar as definições dogmáticas, tendo em vista que estamos diante de uma categoria vigorosamente pulsante, que de fato deve apresentar elementos autobiográficos, mas na qual encontramos incontáveis variantes, tanto em termos de estratégia narrativa, maior ou menor grau de utilização de eventos factuais, etc. que tornam as acepções categóricas ingênuas e parciais.

As fronteiras que distinguem as diferentes categorias das "escritas de si" são tênues, tanto que Bakhtin (2011, p. 138), apesar de reconhecer as diferenças entre biografia e autobiografia, no decorrer de sua análise, acaba tratando-as genericamente de forma similar:

Não existe um limite acentuado e de princípio entre a autobiografia e a biografia, e isso é de grande importância. Diferença existe, evidentemente, e pode ser grande, mas não se situa no plano da diretriz axiológica básica da consciência. Nem na biografia, nem na autobiografia o eu-para-si (a relação consigo mesmo) é elemento organizador constitutivo da forma.

Bakhtin chama a atenção para o fato de que, embora compartilhem episódios presentes no enredo, autor e personagem continuam sendo categorias distintas na narrativa. Outrossim, aponta a base da intersecção:

É claro que o autor, como elemento constitutivo da obra de arte, nunca coincide com a personagem: eles são dois, mas entre eles não há contraposição de princípio, seus contextos axiológicos são congêneres, o portador da unidade da vida - a personagem- e o portador da unidade da forma- o autor- pertencem ambos ao mesmo universo de valores (BAKHTIN, 2011, p. 151).

O surgimento da narrativa biográfica proporciona uma alteração na relação do protagonista com o mundo, segundo as tradicionais definições de Lukács. De acordo com o autor húngaro, o que diferencia o protagonista da epopeia e do romance é que na épica ele representa os valores sociais vigentes, enquanto no romance, o protagonista está em desajuste com a sociedade em que vive, ideia também desenvolvida por lan Watt (2010, p. 13):

O romance é a forma literária que reflete mais plenamente esta orientação individualista e inovadora. As formas literárias anteriores refletiam a tendência geral de suas culturas a conformarem-se à prática tradicional do principal teste da verdade: os enredos da epopeia clássica e renascentista, por exemplo, baseavam-se na História ou na fábula e avaliavam-se os méritos do tratamento dado pelo autor segundo uma concepção de decoro derivada dos modelos aceitos no gênero.

Já na biografia (ou auto- biografia), o protagonista insere-se num percurso linear da vida cotidiana, sem que necessariamente haja um conflito axiológico com o restante da sociedade. Em certo sentido, as seguintes palavras de Bakhtin (2011, p. 213) atestam nossa tese:

O enredo da forma biográfica, à diferença do romance de viagem e do romance de provação, não é construído com base nos desvios em relação ao curso normal e típico da vida, mas precisamente nos elementos basilares e típicos de toda a trajetória vital: nascimento, infância, anos de aprendizagem, casamento, construção do destino, trabalho e afazeres, morte, etc.

O que é preciso observar, principalmente nas narrativas contemporâneas, é que existem distintos graus de inserção da biografia do autor na obra artística. É evidente que os 


\section{$=$ TRAMA $=$}

autores desde sempre introduziam experiências por eles vivenciadas em seus textos, entretanto, hoje em dia, com o aumento significativo do acesso que temos às informações (seja sobre as biografias dos autores, processos criativos por eles adotados, etc.) estas "intromissões" autobiográficas são mais facilmente identificáveis. Ademais, mesmo em textos considerados "não biográficos", os autores dedicam-se menos a ocultar a factualidade de determinados eventos.

Na medida em que avançam os estudos de teoria literária (de forma ampla), e sua divulgação, os leitores se veem mais bem instrumentalizados para desfrutar e analisar as obras (o que é um processo natural, que ocorre nas diversas searas do conhecimento). Este leitor, menos ingênuo, passa a ter ciência de que o trabalho do escritor com a biografia não é apenas de transcrição de fatos de uma vida real, mas sim um complexo trabalho estético, como afirma Bakhtin (2011, p. 152): "A biografia não é uma obra e sim um ato estetizado orgânico e ingênuo, praticado em um mundo imediato investido de autoridade semântica, por princípio aberto mas organicamente autossuficiente."

A mescla entre eventos reais e ficcionais sempre fez parte da produção literária. O que ora ocorre é que os escritores nos apresentam esta mescla de forma menos velada, o que, sob certo aspecto, enriquece o objeto estético, em ambos sentidos (ao semear a dúvida produtiva). Exemplo disso é o sucesso de certas biografias ficcionais produzidas pelo escritor argentino Jorge Luis Borges, inclusive de "escritores" (inexistentes no mundo factual), que, ironicamente, chegaram a ser de fato procurados em livrarias...

\section{O PORTADOR DA UNIDADE DA FORMA}

Tendo em vista que o tema deste estudo problematiza questões relativas à autobiografia e suas variantes, faz-se relevante atentarmos para certos eventos da biografia do artista que aqui analisamos. Porto-Alegrense, nascido em 1970, Duca Leindecker tem uma sólida carreira como músico, já sua incursão na Literatura (no papel de escritor) é posterior, mas já conta com boa aceitação da crítica e simpatia dos leitores (seu primeiro livro, A casa da esquina, tornouse um bestseller com mais de doze edições).

Duca é oriundo de uma família composta por três irmãos, o mais novo, Luciano, foi seu parceiro na banda Cidadão Quem. Sua mãe é Professora de História, já o pai, falecido quando Duca tinha oito anos de idade, era advogado. Este acontecimento, por sinal, é algo de extrema relevância na produção literária do autor, tanto que, na maioria de suas entrevistas, ele menciona o fato de ter perdido o pai em tenra idade. Além disso, inúmeras passagens em seus textos (que adiante serão mais detidamente analisados) focalizam ou tangenciam tal perda.

A precocidade com que Duca entrou no mundo da música profissional impressiona. Possivelmente a partir da influência do avô e do irmão mais velho, que tocavam violão, aos onze anos já decidiu que seria músico. No entanto, não se tratava de um pueril desejo de menino, pois aos treze, já tocava na noite de Porto Alegre, e aos catorze ganhou o prêmio (promovido pelo jornal de maior circulação no Rio Grande do Sul) de melhor guitarrista do ano. Fez parte, ainda menino, da Bandaliera, importante banda do rock gaúcho dos anos 80, e aos 17 anos já gravava seu disco solo, conforme informações fornecidas pelo próprio website do autor.

Seu sucesso mais longevo, todavia, deu-se na banda Cidadão Quem, a qual ajudara a fundar, juntamente com o irmão, Luciano Leidecker (contrabaixo), e CauHafner (bateria), e da qual era guitarrista e vocalista. A banda surgiu em meados dos anos 1990, e encerrou suas atividades em 2014, com a morte do segundo componente, Luciano. Cau havia falecido em um acidente de paraquedas, em 1999, o que abalou Duca profundamente, e esta passagem tem importância na escrita de seu segundo livro, $A$ favor do vento, obra que será o corpus de análise do nosso estudo. A partir de então, Duca segue sua carreira como músico, agora solo, e outros 


\section{$=$ TRAMA $=$}

projetos em parceria com outros músicos. Em paralelo, desenvolve rica atividade literária, seja na publicação de livros (três até o momento: A casa da Esquina-1999; A favor do Vento- 2002; O menino que pintava sonhos- 2013), ou palestrando.

\section{O PROCESSO CRIATIVO}

Leindecker define sua escrita como simples, muito embora feita com atenção, esmero e parcimônia, afirma que já chegou a descartar livros completos por não os julgar dignos de chegar ao público. Além disso, já reescreveu um de seus livros, mudando o foco narrativo a fim de obter o efeito desejado.

Uma característica saliente em todos os seus livros é a utilização de episódios factuais de sua vida na obra ficcional. Em seu primeiro livro, A casa da esquina (2014), esta faceta aparece de forma mais constante, não se trata de uma autobiografia linear ou totalizadora, composta exclusivamente de eventos vivenciados pelo autor, mas aproxima-se bastante disto. O romance tem como evento predominante no enredo a trajetória de uma família que vive o drama da doença, e posterior morte, da figura paterna, ou seja, similar ao ocorrido de fato com Leindecker. O autor afirma que sua escrita parte de um conjunto de inspirações, inclusive de coisas que acontecem na sua vida. Ele vê a arte, seja a Música ou a Literatura, como verdade, mesmo que tenha cara de ficção, como ele próprio afirma: “...tudo é ficção, né, a gente chama tudo de ficção, mas isso é uma desculpa pra gente falar das nossas coisas e dizer que não é a gente, mas na verdade é a gente mesmo que tá ali” (QUEROSENE LABS, 2017).

Preocupação importante do autor, de acordo com entrevista concedida a Machado (2017), principalmente em virtude do sucesso de seu primeiro livro, é não reproduzir uma fórmula bem-sucedida, mas seguir buscando desenvolver arte de forma criativa (compreensão adquirida também a partir da vasta experiência na composição de músicas e letras).

Um tema central na obra de Leindecker é a perda de pessoas próximas, seja pela morte, prisão, ou outras circunstâncias da vida. Entretanto, tal característica não torna repetitivos seus livros. A favor do vento (2014), sua segunda obra literária, enfoca outro trauma, além de outra estratégia narrativa, que adiante serão analisados.

Ainda que seja também eivado de eventos autobiográficos, o terceiro livro do autor, $O$ menino que pintava sonhos (2014), trata de conflitos ora vivenciados pelo autor, como, por exemplo, a incerteza sobre a autenticidade de um talento artístico nato, ingenuidade versus convicção, etc. Muito embora o autor diga que o conflito é maior que a forma, neste caso, a forma é fundamental para o sucesso narrativo, pois se trata de um narrador em primeira pessoa absolutamente confiante de seus atos, beirando o egocentrismo ingênuo e certa presunção. $A$ utilização de tal tipo de narrador é rara na Literatura, mas, neste caso, atende de forma eficiente a um objetivo específico.

\section{ESCRITA COM VIDA PRÓPRIA}

A favor do vento (2014), assim como seu primeiro livro, é permeado por elementos autobiográficos. No entanto, o cerne da obra ora analisada é outro, o trauma que move o artista a depurar, através da arte, suas inquietações é distinto neste segundo livro. A morte de um amigo e companheiro na banda Cidadão Quem, CauHafner, em um acidente de paraquedas, moveu Leindecker para a escrita desta obra.

Todavia, o trabalho artístico de cifrar e decifrar dá vida própria ao novo enredo. Segundo o próprio autor, em entrevista à sua editora (QUEROSENE LABS, 2017), ele transfere a figura do falecido amigo para a esposa do protagonista, que se suicidara. Tal transposição, e os arranjos para a obtenção da "verossimilhança", conferem ao romance autonomia suficiente para ser lido com deleite sem as informações biográficas do autor. 


\section{$=$ TRAMA $=$}

Curioso, na estrutura narrativa, é que o texto é estruturado com duas temporalidades, em vinte e nove capítulos intercalados, alternadamente falando do passado do protagonista e de seu presente. Contudo, estas narrativas começam a entrecruzar-se a partir do capítulo vinte e cinco, quando começa a ocorrer a solução do conflito interno que inquietara o protagonista (o protagonista não é nomeado na obra, entretanto, quando ainda jovem roadie de uma banda, fora apelidado de Silverclai).

O narrador do texto também apresenta variações demandadas pelo andamento da narrativa. As duas temporalidades são narradas em primeira pessoa, ora como protagonista dos episódios, ora como testemunha, o que atribui a este narrador certa onisciência, mesmo sendo em primeira pessoa. Não obstante, o fluxo de informações fornecido por esse narrador é distinto nos dois momentos da narrativa. Quando narra sobre o passado, que tematiza eventos mais pitorescos vivenciados por uma banda de Rock dos anos 80, há abundância de informações e detalhes, o que pouco desencadeia inferências subliminares:

Na Verdade, eu sabia todas as músicas, mas nunca tinha encarado uma plateia com a guitarra em punho. Uma guitarra, não um vilão Trovador, destes que a gente encontra em qualquer escola estadual. Uma Stratocaster 68 Americana com o adesivo do Van Halen ligada aos pedais que eu sempre montava com o maior cuidado... (LEINDECKER, 2014, p. 119).

Já quando o foco narrativo se detém no presente, o narrador passa a ser mais lacunar, reflexivo, instável, de certa forma confessional, e menos episódico, com menos segurança das informações que fornece, contribuindo para o mistério que será esclarecido ao final: "Não sei exatamente por que vim para cá. O certo é que já estou aqui há dois dias e não tenho a menor vontade de voltar. Sinto uma intuição estranha que parece me desafiar, escondendo de mim as razões desta vinda" (LEINDECKER, 2014, p. 9).

Neste sentido, o romance de DucaLeindecker alinha-se com uma série de outros romances contemporâneos da Literatura Brasileira que apresentam um narrador não convencional, que, segundo Jaime Ginzburg (2015, p. 200), dista-se do modelo tradicional de representação, trazendo novas perspectivas a partir de narradores "descentrados":

[...] Mendes, Tezza, Gonçalves, Moscovich e Carella se afastam de uma tradição brasileira, no interior da qual é necessária uma presença (como personagem ou narrador) que corresponde, no todo ou em parte, aos valores da cultura patriarcal. Esse modelo prioriza homens brancos, de classe média ou alta, adeptos de uma religião legitimada socialmente, heterossexuais, adultos e aptos a dar ordens e sustentar regras.

Ademais, a variação entre temporalidades proporciona também diferenças no estilo narrativo e na linguagem utilizada em cada momento. Os eventos do passado são narrados com uma linguagem despojada, com reprodução, por vezes, da linguagem oral utilizada pelos personagens: "Me dá quatro dedo di pinga e dois ovo em conserva" (LEINDECKER, 2014, p. 24). Por outro lado, o presente do narrador é exposto em linguagem padrão, mas sem barroquismos que comprometeriam a unidade da obra.

Podemos perceber relações autobiográficas já na dedicatória do livro: "Este livro é dedicado às bandas Prize, Bandaliera e Cidadão Quem" (LEINDECKER, 2014, p. 5), bandas pelas quais Leindecker passou, e de onde provavelmente extraiu alguns dos episódios constantes no enredo da obra em questão, sobretudo os que focalizam Silverclai, no passado do protagonista. 


\section{$=$ TRAMA $=$}

Outro aspecto coincidente entre a vida do autor e o enredo da obra é o espaço em que transcorre a narrativa. Do mesmo modo que há duas temporalidades na narrativa, há dois espaços predominantes: o primeiro, Porto Alegre, cidade natal do autor, ambienta os acontecimentos de quando o protagonista ainda era jovem. Neste caso, o espaço é apresentado apenas de maneira pragmática, contribuindo na construção de um contexto que não faz parte de reflexões mais detidas.

Já o segundo espaço apresentado no romance, Pinhal, praia do litoral gaúcho, tem fundamental papel simbólico e afetivo para o momento enfrentado pelo protagonista, a seguinte citação é um válido exemplo neste sentido:

Quase quinhentos quilômetros de extensão sem sequer um pequeno rochedo que remeta àquela imagem tropical contida nos folhetos turísticos. O mar revolto não desvia meu olhar firme que permanece em direção ao norte. As águas ali não têm o azul dos outros mares, nem a simetria das ondas calmas com suas cortinas de spray. O vento é o pai desta pintura turva e também o pai das lembranças que o meu olhar vê nos vazios deste lugar (LEINDECKER, 2014, p. 7).

O inusitado de uma temporada na praia em pleno inverno sul rio-grandense e a frialdade na descrição desta praia, sem os coloridos habituais, coadunam-se com a inquietação do personagem, com seus tormentos afetivos e psicológicos.

Outrossim, Pinhal é uma praia frequentada efetivamente por Leindecker e sua família. Em virtude de seus problemas respiratórios, um médico sugerira a compra de uma casa na praia, o que o pai de Leindecker fizera. Assim sendo, Pinhal representa também um espaço afetivo, até certo ponto familiar, para onde o protagonista (e quiçá o autor) recorre em um momento de profunda crise. Deste modo, o narrador não se exime de demonstrar o apreço por este espaço: "No cenário cinza das praias do Rio Grande se esconde uma beleza única, que talvez seja vista apenas pelos que nelas cresceram e nelas depositaram o amanhecer deste passeio rápido pela vida." (LEINDECKER, 2014, p. 126)

Tal espaço passou a dividir o papel de lar com a cidade de Porto Alegre, tanto na esfera ficcional quanto factual. (Leindecker ainda possui uma canção chamada Pinhal, que consta no terceiro álbum da banda Cidadão Quem, chamado Spermatozoon, lançado em 1998, canção de cunho narrativo e nostálgico, remetendo a um período de tenra juventude).

\section{PASSADO}

A primeira das duas temporalidades constantes no romance desenvolve-se no passado do protagonista e, apesar de não encontrarmos comprovações, nem nas pequenas biografias do autor, nem nas entrevistas disponíveis e aqui utilizadas, muitos destes episódios podem, e devem, de fato ter ocorrido também com o autor da obra. Trata-se de um momento em que o protagonista, com dezesseis anos de idade, é o roadie de uma banda de Rock, em Porto Alegre, cujo contexto é assim definido pelo narrador:

Estávamos vivendo os anos oitenta. Foi a época em que o rock brasileiro deu um boom. Milhares de bandas surgiam em todos os cantos do país e a juventude vivia e via no rock a trilha sonora perfeita para a abertura política aguardada há mais de vinte anos (LEINDECKER, 2014, p. 23).

A tríade "sexo, drogas e rock'n roll" está presente no ambiente vivenciado por Silverclai, muito embora ele quase que exclusivamente testemunhe tal prática. Trata-se da iniciação do adolescente no mundo artístico e no cenário do Rock, o que the proporciona algumas experiências positivas (conhecimento dos equipamentos, logística, relacionamento entre 


\section{$=$ TRAMA $=$}

membros de uma banda...), já outros com consequências desagradáveis (overdose de cocaína sofrida por um integrante da banda, calotes financeiros sofridos pelos músicos, embriaguez que Ihe acarretou uma reprimenda do empresário da banda...).

Indubitavelmente, em se tratando do mundo artístico dos anos 1980, são narradas cenas pitorescas e cômicas, como a em que o ônibus da banda ficou sem combustível:

Nem preciso dizer que a cena foi incrível, a estrada deserta e uma banda de rock empurrando um ônibus. Pra dizer a verdade, eu achei que seria mais difícil fazer aquela coisa se mover; no entanto, conseguimos chegar até a lomba, mas a porqueira não pegou (LEINDECKER, 2014, p. 64).

Outra, em que uma fã, em pleno camarim, ao pedir autógrafos e paquerar com os músicos, vomita o lugar todo, em decorrência do excesso de álcool, o que foi encarado com gracejo pelos presentes.

Ademais, ocorre neste período um fato decisivo na trajetória do protagonista, sua transição de roadie para músico profissional. Silverclai, em uma ausência inesperada do guitarrista da banda, que se encontrava em uma delegacia, por ter participado de uma briga (o que se soube depois) é chamado para assumir o instrumento naquele show:

Quando dei a primeira palhetada não acreditei na pressão que veio em minha direção. Eu só afinava a guitarra, nunca tinha tocado pra valer. Nunca tinha sentido o volume que vem da soma dos instrumentos e dos monitores do palco. Depois da primeira música tudo passou voando e, como num piscar de olhos, estava no camarim conversando com todos que me cumprimentavam. Do meio dos fãs surgiu o Monteiro:

-Parabéns! Foi muito bom mesmo, mas não esquece que tu ainda tem que desmontar tudo (LEINDECKER, 2014, p. 27).

A partir daí, não poderia mais prescindir de tal emoção e resolveu deixar a banda, com o apoio de todos os membros, que viam nele um garoto de talento. É plenamente viável que a descrição desta emoção corresponda à que Leindecker viveu em seu início, e porventura viva a cada vez que sobe ao palco.

\section{PRESENTE}

A segunda temporalidade da narrativa centra-se no presente do protagonista, em uma espécie de retiro, em Pinhal (quase deserto em função do inverno), que o narrador chama de autoterapia. Ele dosa as informações fornecidas, a fim de criar um mistério sobre as motivações do protagonista, que só são esclarecidas ao final do enredo.

É possível, mais uma vez, relacionar acontecimentos vividos pelo autor e pelo protagonista, apesar de artisticamente velados e estrategicamente alterados. Leindecker perdeu o amigo e colega de banda Cau Hafner, em um acidente de paraquedas, esporte para o qual levara o parceiro. Além disso, o protagonista do romance perde a esposa, que comete suicídio. Leindecker confirma a relação em entrevista a sua editora (QUEROSENE LABS, 2017), acrescenta ainda que o paraquedismo é uma espécie de suicídio contido, no limite da sobrevivência, abre-se o paraquedas no limiar entre a queda e a aterrisagem. É o trauma da morte do amigo que Leindecker usa como mote para $A$ favor do vento.

Este segundo momento da narrativa estrutura-se de forma diversa do anterior. Quando trata do presente do protagonista, há mais reflexões do que acontecimentos, torna-se uma narrativa introspectiva, memorialística, em tom confessional: 


\section{$=$ TRAMA $=$}

Luto contra mim mesmo nesta tentativa frustrada de me desconectar do próprio pensamento. Quanto mais eu tento, mais altas são as vozes que me importunam e não me deixam relaxar. Alguém passeia pelos meus devaneios em conversas intermináveis sem que eu crie mais do que apenas uma vaga familiaridade. (LEINDECKER, 2014, p. 28)

O aparecimento de duas personagens, Jordana e Cássia, biólogas que foram à praia para realizar estudos, é fundamental para as reflexões do protagonista, tendo em vista que elas têm visões de mundo quase que opostas, e debatem sobre fidelidade, evolução do ser humano, relacionamentos, etc., inquietações centrais no romance. Ademais, em função de sua atividade profissional, tratam a relação entre vida e morte de maneira mais natural do que as demais pessoas: "-É... Por outro lado a gente está acostumada a entender o ciclo natural da vida. O lado importante da seleção natural das espécies e de como a morte pode ser importante para todo o processo" (LEINDECKER, 2014, p. 98).

Não obstante, o contraponto gerado pela distinta visão de mundo que Cássia (pragmática) e Jordana (humanística) apresentam, pode representar os valores do protagonista nos dois momentos da narrativa, do menino e do homem. Adiante, o narrador explicita o fenômeno que o fez buscar a autoterapia: "Existem muitos mecanismos de defesa para administrar um acontecimento indesejado, e o mais comum deles, base para os demais, é mesmo a negação através do esquecimento" (LEINDECKER, 2014, p. 143).

O bloqueio de memória causado pelo trauma da morte fez o protagonista refletir sobre toda sua existência, questionar seu papel e sua trajetória. Talvez isto explique o fato do protagonista não ser nomeado, ele tampouco sabe quem é de fato como ser humano, diferentemente do que ocorre na primeira parte da narrativa, em que é nomeado e não enfrenta dilemas existenciais, como o que segue: "Não sei até onde vão estes meus devaneios, mas o certo é que preciso descobrir a qual lugar pertenço e o que mais existe além das lembranças daquelas viagens..." (LEINDECKER, 2014, p. 53).

Há, de forma gradual, um entrecruzamento entre as temporalidades da narrativa (a partir do capítulo XXV), em que o protagonista vai maturando suas inquietações. Sua epifania só ocorre, entretanto, quando ouve sua própria história narrada por Jordana, sem que ela saiba da coincidência:

\footnotetext{
-Eu nem gosto muito de lembrar dessa história, ela estava no auge da vida e era apaixonada pelo marido, que foi, na verdade, seu primeiro namorado e que também era apaixonado por ela. Eu não o conheci, mas do jeito que ela falava dava pra sacar que os dois eram grudados. Um dia, o cara chegou em casa e encontrou a Helena na banheira com os pulsos cortados. Os comentários foram de que ele surtou e ficou internado um tempo... (LEINDECKER, 2014, p. 131).
}

Para a ocorrência de tal evento, é criada uma ambientação quase ritualística: um luau, em que assavam peixe em uma fogueira feita ao chão, ao sabor do vinho, algo ligeiramente próximo ao que acontecia ao homem primitivo, o que é alvo de comentários dos personagens.

O protagonista decide então seguir seu caminho, voltar para casa e retomar sua vida, reconfigurada, assim como Leindecker, após a morte do amigo, decide seguir com a Cidadão Quem, pois, o que acreditamos ser uma conclusão de ambos, "A favor do vento, minhas passadas ficam mais leves." (LEINDECKER, 2014, p. 141).

\section{CONSIDERAÇÕES FINAIS}

A análise da obra em questão comprovou a tese por nós levantada ao longo do estudo, de que a narrativa de cunho autobiográfico introduz no romance uma nova relação entre o 


\section{$=$ TRAMA $=$}

protagonista e o mundo circundante. Diferentemente do que ocorre na epopeia (em que o protagonista conglomera em sua figura os valores, de maneira ampla, da sociedade na qual se insere) e de maneira distinta também à postura do protagonista do romance tradicional frente à sociedade (que é de conflito), o personagem da autobiografia muitas vezes possui inquietações de outra ordem, interior, familiar, existencial, etc. Em A favor do vento (2014), o narrador personagem, durante boa parte do enredo, sequer sabe o alvo da busca que empreende, tenta encontrar-se consigo a fim de retomar sua vida, suas angústias se dão em decorrência de fatos naturais da vida, tristes, mas que fazem parte do ciclo, o que compreende, dentre outros motivos, a partir do breve convivio que tem com as duas biólogas.

A estratégia mais utilizada por Leindecker na introdução de elementos autobiográficos no enredo é a de constantemente "cifrar e decifrar". Muitos episódios do romance, devido à similaridade com a vida do autor, possivelmente sejam factuais, alguns são facilmente confirmados, outros continuam e continuarão sendo possibilidades. Há uma gama de eufemismos, adaptações contextuais, omissões, etc. que semeiam ao romance a dúvida produtiva, que inquieta o leitor, numa provocação estimulante e intelectualmente enriquecedora na procura pela intersecção entre autor e personagem.

Entretanto, mesmo ao ignorarem-se as intromissões autobiográficas no texto, ele tem autonomia para sustentar-se como obra de arte autônoma, o leitor que buscar ficar alheio à referida relação poderá fruir de uma obra de arte que explora elementos estéticos de forma fecunda. A título de exemplo, podemos citar a fusão de enredos, com a manutenção da homogeneidade da obra; a exploração de possibilidades inusitadas da figura do narrador; introdução estratégica de personagens; um mistério costurado de forma competente e que mantém a tensão até o fim da narrativa... Enfim, a biografia do autor enriquece o texto, mas ele se mantém como objeto de qualidade também em função de outras virtudes. Com base na vida do autor, adquire vida própria.

\section{REFERÊNCIAS}

BAKHTIN, Mikhail. Estética da criação verbal. Trad. Paulo Bezerra. 6.ed. São Paulo: WMF Martins Fontes, 2011.

BAKHTIN, Mikhail. Questões de Literatura e Estética - A teoria do romance. 7.ed. São Paulo: Hucitec, 2014

D'ONOFRIO, Salvatore. Teoria do texto: prolegômenos e teoria da narrativa. São Paulo: Ed. Ática, 2002.

GENETTE, Gérard. Discurso da narrativa. 3. ed. Lisboa: Vega, 1995.

GINZBURG, Jaime. O narrador na literatura brasileira contemporânea. Disponível em:<http://riviste.unimi.it/index.php/tintas/article/view/2790>. Acesso em: 11 jul. 2017.

LEINDECKER, Duca. A casa da esquina. 11 ed. Porto Alegre: L\&PM, 2014.

LEINDECKER, Duca. A favor do vento. 4 ed. Porto Alegre: L\&PM, 2014.

LEINDECKER, Duca. O menino que pintava sonhos. 3 ed. Porto Alegre: L\&PM, 2014.

LEINDECKER, Duca. Bio. Disponível em:<http://www.ducaleindecker.com.br>. Acesso em 15 ago. 2017.

LEITE, Ligia Chiappini M. O foco narrativo. 10 ed. São Paulo: Ática, 2004.

LUKÁCS, Georg. Teoria do Romance. Trad. José Marcos Mariani de Macedo. São Paulo: Editora 34, 2000.

MACHADO, Juremir. Livro Aberto: Entrevista com Duca Leindecker. Disponível em:<

https://www.youtube.com/watch?v=hL6D17QWvVA>. Acesso em 21 ago. 2017.

QUEROSENE LABS. Palavra de escritor: Duca Leindecker. Disponível em:<http://www.lpm-

webtv.com.br/site/default.asp?Template=../multimidia/layout_exibir.asp\&MidialD=836072\&TroncolD=539000

\&SecaolD=711710>. Acesso em 08 ago. 2017.

REFINSKI, Márcia. Entrevista com Duca Leindecker. Disponível

em:<https://www.youtube.com/watch?v=kEHjVBxYJzc>. Acesso em 10 ago. 2017

WATT, lan. A ascensão do romance. Trad. HildegardFeist. São Paulo: Companhia das Letras, 2010. 